Geografia e Ordenamento do Território, Revista Eletrónica

Centro de Estudos de Geografia e Ordenamento do Território

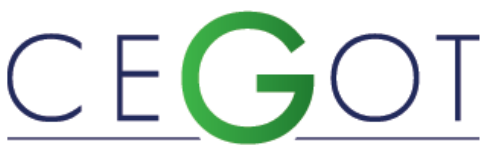

Centro de Estudos de Geografia e Ordenamento do Território

http://cegot.org

ISSN: 2182-1267

Paixão, S.

Escola Superior de Tecnologia da Saúde de

Coimbra - CEGOT

supaixao@estescoimbra.pt

Sá, N.

Escola Superior de Tecnologia da Saúde de

Coimbra nelsonsa@estescoimbra.pt

Simões, J.

Escola Superior de Tecnologia da Saúde de

Coimbra joana.tsimoes@gmail.com

Gaminha, I.

Escola Superior de Tecnologia da Saúde de

Coimbra inescarolinagaminha@hotmail.com

\title{
Pegada ecológica de uma instituição do ensino superior portuguesa
}

Referência: Paixão, S. et al. (2012). Pegada Ecológica de uma Instituição do Ensino Superior Portuguesa. Revista de Geografia e Ordenamento do Território, n.o 1 (Junho). Centro de Estudos de Geografia e Ordenamento do Território. Pág. 165 a 180

\section{Resumo}

O equilíbrio entre a vida humana e o ambiente só é possível se, entre outros aspetos, a vivência dos seres humanos for realizada em simbiose ambiental, ou seja, da forma mais ecológica possível. De forma a constatar a existência dessa simbiose, criaram-se 
diversas ferramentas para avaliar a sustentabilidade, tal como a Pegada Ecológica (PE). O presente estudo tem como principal objetivo o cálculo da PE da Escola Superior de Tecnologia da Saúde de Coimbra (ESTeSC), comparando os valores obtidos com os dois estudos anteriormente efetuados com o mesmo âmbito. O questionário que foi disponibilizado à amostra foi adaptado do existente na plataforma www.myfootprint.org. Comparando os resultados obtidos com anos anteriores, é possível verificar que a PE da ESTeSC desde 2009 tem vindo a diminuir na generalidade dos grupos estudados. Apenas o grupo dos docentes aumentou a sua PE desde o ano de 2010, sendo que a média da ESTeSC no ano de 2011 foi de 4,8 hectares globais.

Palavras-Chave: Sustentabilidade Ambiental; Pegada Ecológica; Desenvolvimento Sustentável; Educação Ambiental

\begin{abstract}
The balance between human life and the environment is only possible if, among other things, the experience of man is held in environmental symbiosis, i.e. the more environmentally friendly way possible. In order to verify the existence of this symbiosis, it was created several tools to assess sustainability, such as the Ecological Footprint. This study has as main objective the calculation of the Ecological Footprint of the School of Health Technology of Coimbra, comparing the values obtained with two studies with the same scope. The questionnaire that was made available to the sample was adapted from the existing one in the platform www.myfootprint.org. Making a comparison with previous years it was verified that the Ecological Footprint in ESTeSC since 2008 has declined in most groups. Only the group of teachers increased their Ecological Footprint from 2009. The average of Ecological Footprint at ESTeSC in 2010 was 4,8 ha.
\end{abstract}

Keywords: Environmental Sustainability, Ecological Footprint, Sustainable Development, Environmental Education 


\section{Introdução}

Segundo Parente, na sua época, o filósofo Platão referiu que "o total de pessoas não poderia ser fixo sem se considerar a área e os estados vizinhos", relativamente à capacidade de suporte da Terra. Atualmente, com o crescimento desmedido da população, aliado à sofisticação tecnológica, acentua-se a problemática da capacidade de sustentabilidade do planeta (Parente, 2007).

O equilíbrio entre a vida humana e o ambiente só é possível se, entre outros aspetos, a vivência dos seres humanos for realizada em simbiose ambiental, ou seja, da forma mais ecológica possível. De forma a constatar a existência dessa simbiose, criaram-se diversas ferramentas de avaliação da sustentabilidade, tal como a Pegada Ecológica (PE). A PE é uma metodologia analítica que possibilita o cálculo (relativamente à área produtiva correspondente) do consumo de recursos e a capacidade de assimilação dos impactes ambientais concebidos por um determinado grupo populacional (Coelho-deSouza, 2009). Pressupõe-se, para esta metodologia, a reflexão da quantidade de área de terreno e mar bioprodutivos necessários para suprimir as necessidades de recursos naturais e assimilação de resíduos, em cada categoria de consumo (Parente, 2007).

Considera-se que, atualmente, as cidades só são capazes de se desenvolver através da apropriação de recursos fora da sua área urbana. Tende então a existir a necessidade de equilibrar recursos e custos ambientais entre os diversos intervenientes no ambiente, de modo a melhorar significativamente o habitat e não transferir para outros ecossistemas ou para gerações vindouras as problemáticas ambientais dos dias de hoje (Coelho-de-Souza, 2009). Alguns estudos indicam que os países mais industrializados apresentam uma PE superior a 6 hectares/pessoa/ano, o que indica que estas regiões necessitam de ocupar espaço fora das suas fronteiras para conseguirem suprimir as suas necessidades de recursos (Parente, 2007).

O presente estudo tem como principal objetivo o cálculo da Pegada Ecológica da Escola Superior de Tecnologia da Saúde de Coimbra (ESTeSC) que é uma instituição de ensino pública inserida no Instituto Politécnico de Coimbra e conta com uma população de cerca de 1300 alunos, 55 docentes a tempo integral e 40 funcionários. 
Objetivou-se aplicar um questionário adaptado do modelo do Center for Sustainable Economy - myfootprint.org, a docentes, funcionários e alunos e comparar os resultados obtidos com os dois estudos efetuados nos dois anos transatos com o mesmo âmbito e metodologia.

Visa-se compreender a distinção entre os oito cursos ministrados na ESTeSC, a saber Audiologia, Análises Clínicas e Saúde Pública, Cardiopneumologia, Dietética e Nutrição, Farmácia, Fisioterapia, Radiologia e Saúde Ambiental, segundo as quatro categorias que abrangem o cálculo da PE, Bens e Serviços, Habitação, Alimentação e Emissões de CO2. Pretende-se, ainda, divulgar os resultados e sensibilizar a comunidade académica para a importância da preservação ambiental e da mudança de hábitos de vida.

\subsection{Estado de arte}

O cálculo da PE, como indicador de sustentabilidade, é dado em "planetas" e em área (hectares globais) que uma pessoa ou população, com o seu estilo de vida, necessita para suprir as suas necessidades. De forma a efetuar o cálculo dos valores que representam os planetas e a área necessários ao sustento do estilo de vida de uma unidade populacional, deverá ter-se em conta o seguinte processo (Parente, 2007):

1. Cálculo da média anual de consumo dos itens particulares dos dados dos agregados, dividindo o consumo total pelo tamanho do agregado.

2. Determinação da área apropriada per capita para a produção de cada um dos principais itens de consumo, dividindo o consumo anual per capita pela produtividade média anual.

3. A área da PE média por pessoa calcula-se pelo somatório das áreas de ecossistema apropriadas por item de consumo de bens ou de serviços.

O referido consumo é separado, globalmente em cinco categorias: alimentação, habitação, transporte, bens de consumo e serviços. (Parente, 2007) Algumas entidades dividem estas categorias em: área de construção, recursos marinhos, floresta, área de pastoreio, área agrícola e pegada de carbono (WWF International, 2010).

Dados do Living Planet Report 2010, demonstram que a terra está a sofrer de exaustão na exploração dos seus recursos, tendo atingindo um ponto em que não tem 
biocapacidade para renovar e assimilar o que lhe é retirado e adicionado conforme se encontra explanado na figura 1 (WWF International, 2010).

Figura 1 - Pegada Ecológica por componente 1961 - 2007

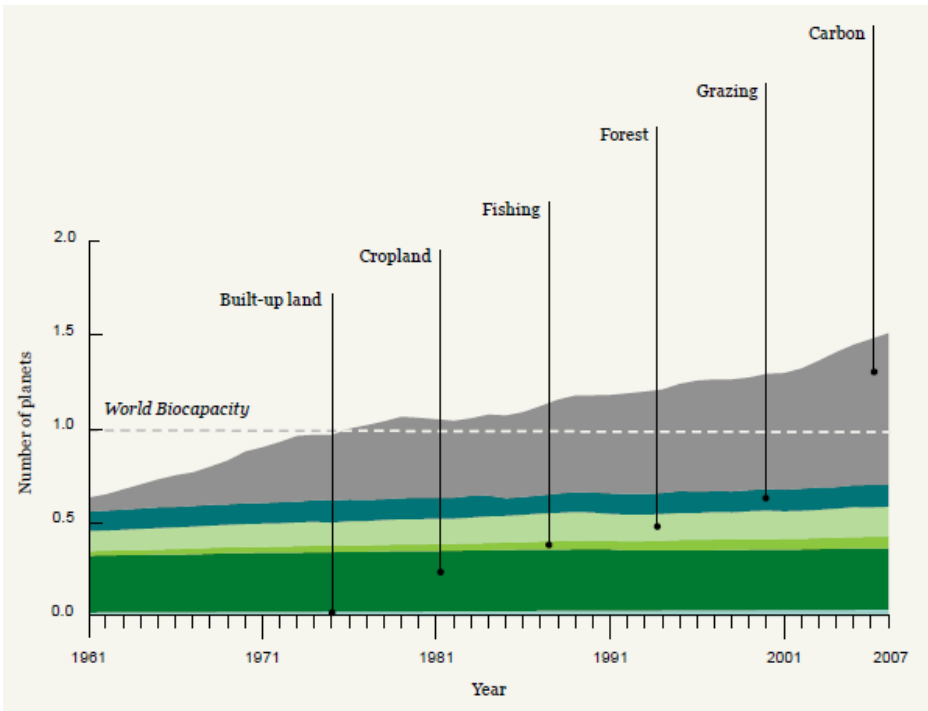

Fonte: WWF - Living Planet Report (2010)

A pegada carbónica cresceu exponencialmente tendo-se verificado nos restantes indicadores uma ligeira subida, ao longo do tempo. Considera-se que na década de 70 a terra atingiu o limiar da sua biocapacidade, tendo em 2007 atingido um ponto em que seriam necessários dois planetas para suprir as necessidades de vida do ser humano.

A partir da figura 2 é possível percecionar-se a evolução da biocapacidade do planeta relativamente à $\mathrm{PE}$.

Figura 2 - Relação entre a PE e a capacidade do planeta, por pessoa (1961-2007)

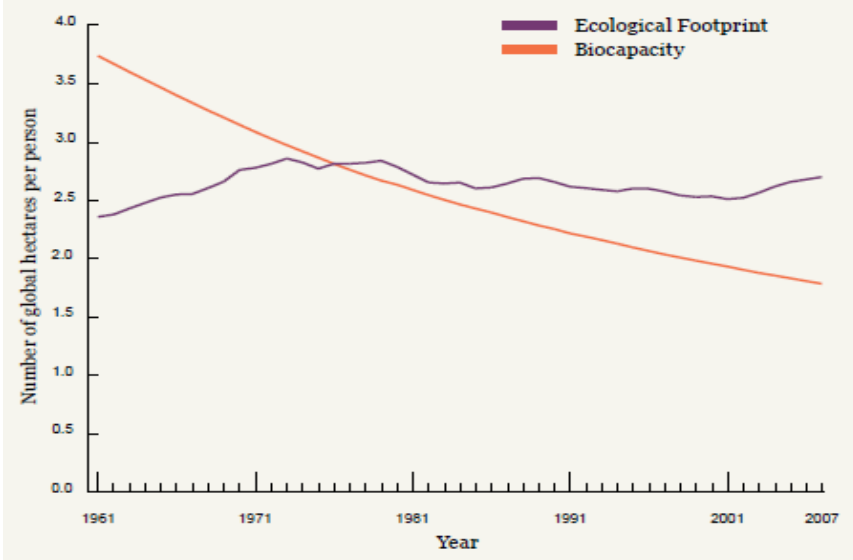

Fonte: WWF - Living Planet Report (2010) 
Pela observação da figura anterior é possível verificar que a biocapacidade total por pessoa no planeta, baixou com o aumento da população.

Por sua vez, na figura 3 representa-se a PE por país e por pessoa.

Figura 3 - Pegada Ecológica por país e por pessoa, 2007

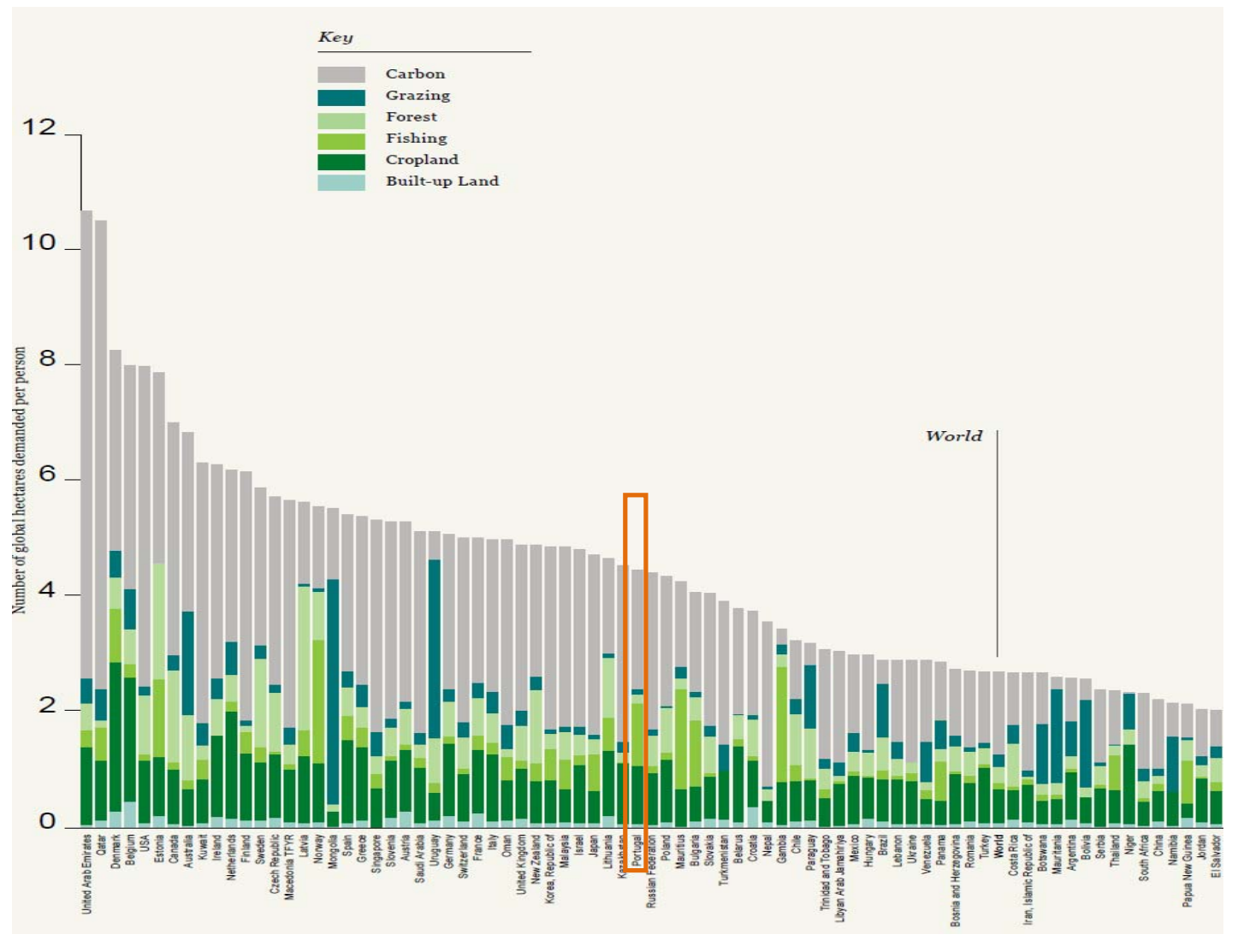

Fonte: WWF - Living Planet Report (2010)

Através da análise do gráfico anterior, é possível constatar que a PE de Portugal se encontra acima da média mundial, dentro dos 40 países do mundo com índice mais elevado. A pegada carbónica é a que ocupa uma posição de maior impacte, seguida da de recursos marinhos e agrícola. Por sua vez, a área de pastoreio é a que consome menos recursos no nosso país.

\section{Metodologia}

O questionário que foi disponibilizado à amostra foi adaptado do questionário existente do Center for Sustainable Economy que se encontra na plataforma www.myfootprint.org. Foi distribuído aos delegados de turma de todos os anos e de 
todos os cursos, entregue a todos os funcionários e docentes que se encontram a tempo inteiro na ESTeSC. O referido documento foi impresso em papel reciclado, de ambos os lados, com ocupação total de uma folha tamanho A4.

A amostra de indivíduos que respondeu ao questionário, relativamente ao número de questionários entregue, encontra-se na tabela 1.

Tabela 1 - Amostra do estudo

\begin{tabular}{|l|c|c|}
\hline \multicolumn{1}{|c|}{ Amostra } & Questionários entregues & Questionários respondidos \\
\hline Alunos Audiologia & 90 & 29 \\
\hline Alunos ACSP & 50 & 27 \\
\hline Alunos Cardiopneumologia & 99 & 54 \\
\hline Alunos Dietética e Nutrição & 77 & 41 \\
\hline Alunos Farmácia & 85 & 41 \\
\hline Alunos Fisioterapia & 92 & 39 \\
\hline Alunos Radiologia & 98 & 44 \\
\hline Alunos Saúde Ambiental & 116 & 59 \\
\hline Docentes & 33 & 25 \\
\hline Não docentes & 28 & 24 \\
\hline \hline TOTAL & 768 & 383 \\
\hline
\end{tabular}

Os questionários preenchidos foram individualmente inseridos na plataforma www.myfootprint.org para fins de tratamento e determinação da Pegada Ecológica, que se colocaram posteriormente numa folha de cálculo da Microsoft Excel. Todo o tratamento de dados e elaboração de gráficos foi executado através do software Microsoft Excel.

No que concerne a questionários com perguntas não respondidas, considerou-se como resposta sempre o pior cenário possível. No que diz respeito à questão número 6 (Qual o número de km que viaja por ano em cada meio de transporte?), quando esta não foi respondida corretamente ou não se obteve qualquer resposta, considerou-se o valor de $4380 \mathrm{~km}$ anuais de automóvel. Este valor foi obtido através do cálculo da distância média diária trabalho-casa dos portugueses. De acordo com dados da Agência Portuguesa do Ambiente (APA), cada português percorre, em média, 10 a $15 \mathrm{~km}$ por dia para o trabalho (Pereira, 2011). Ao final de 365 dias anuais o valor obtido é então 
$4380 \mathrm{~km}$. No caso de perguntas existentes na plataforma que não constavam no questionário distribuído, considerou-se como resposta a pré-selecionada pelo servidor, que é considerada a média nacional.

De forma a converter hectares em planetas e vice-versa, preencheu-se um questionário da plataforma www.myfootprint.org, com dados da média nacional de Portugal e não se colocou qualquer resposta nas questões que permitiam múltipla resposta. Obteve-se a relação de 2,22 planetas para cada 34,91 hectares. Desta forma, converteram-se hectares em hectares por pessoa através de dados de 2007, em que a PE mundial foi de 2,7 hectares por pessoa, correspondendo a 1,5 planetas (Footprint Network).

\section{Resultados}

No que respeita aos alunos dos cursos lecionados na ESTeSC, bem como a docentes e não docentes, foi possível obter os seguintes dados por curso, relativamente à Pegada Ecológica (em hectares e em áreas de consumo).

Gráfico 1 - PE por consumo dos alunos de ACSP

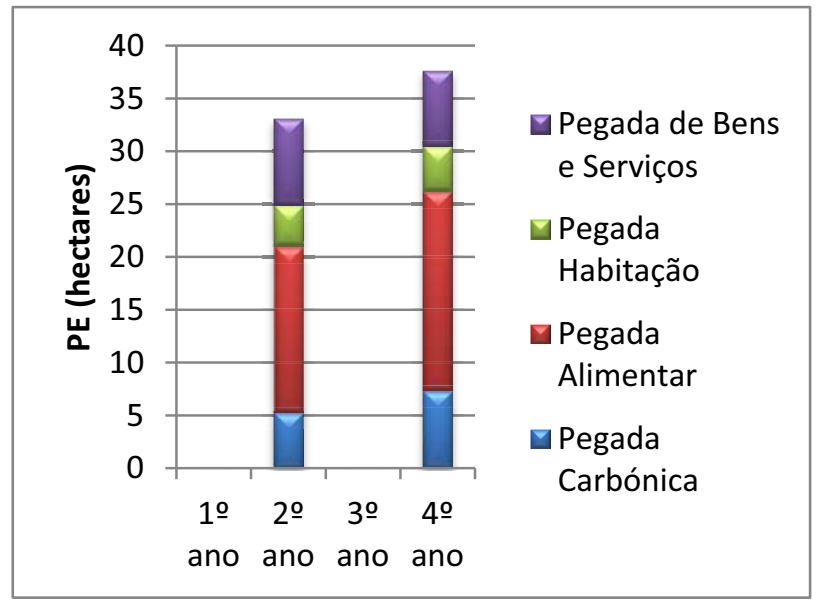

Gráfico 2- PE por consumo alunos de Audiologia

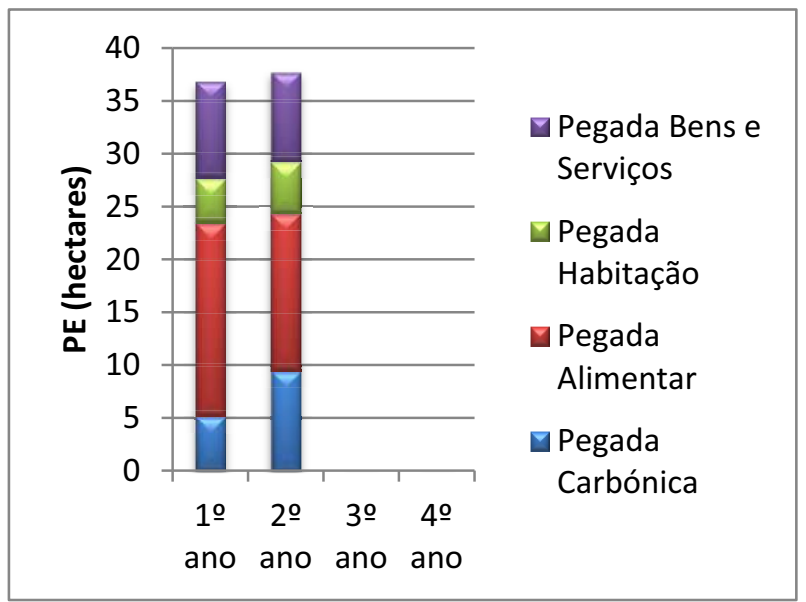


Gráfico 3- PE por consumo alunos de Cardiopneumologia Nutrição

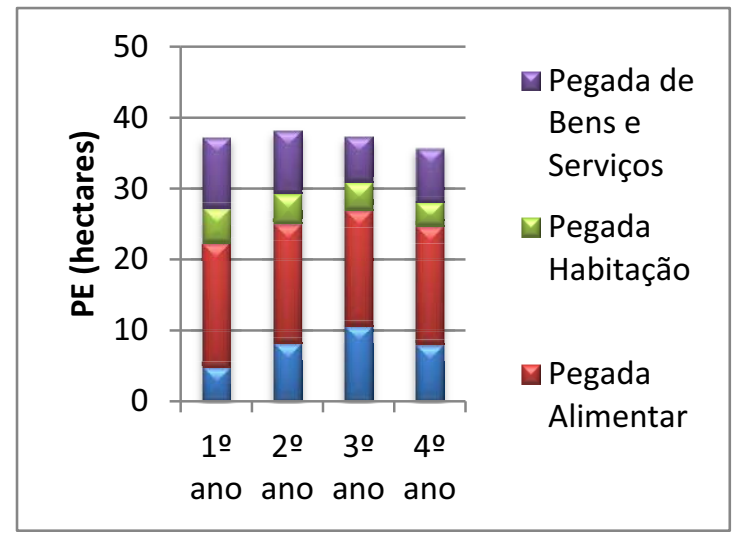

Gráfico 5- PE por consumo alunos de Farmácia

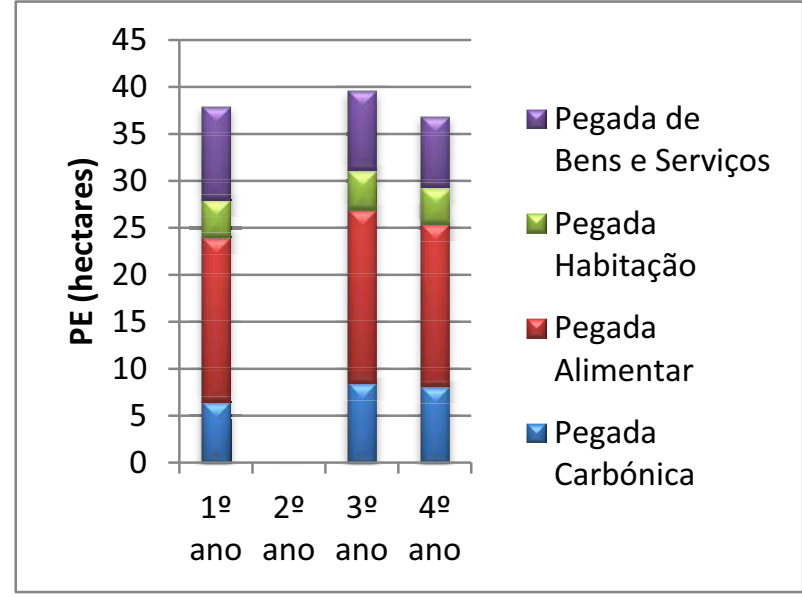

Gráfico 7- PE por consumo alunos de Radiologia

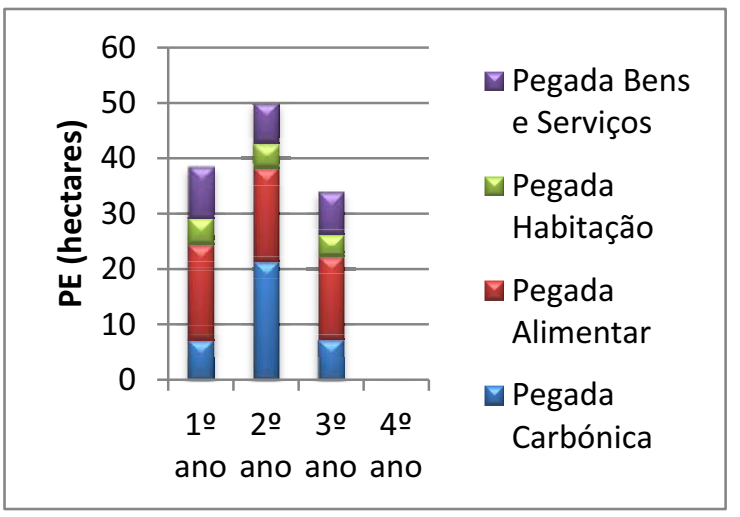

Gráfico 4- PE por consumo alunos de D. e

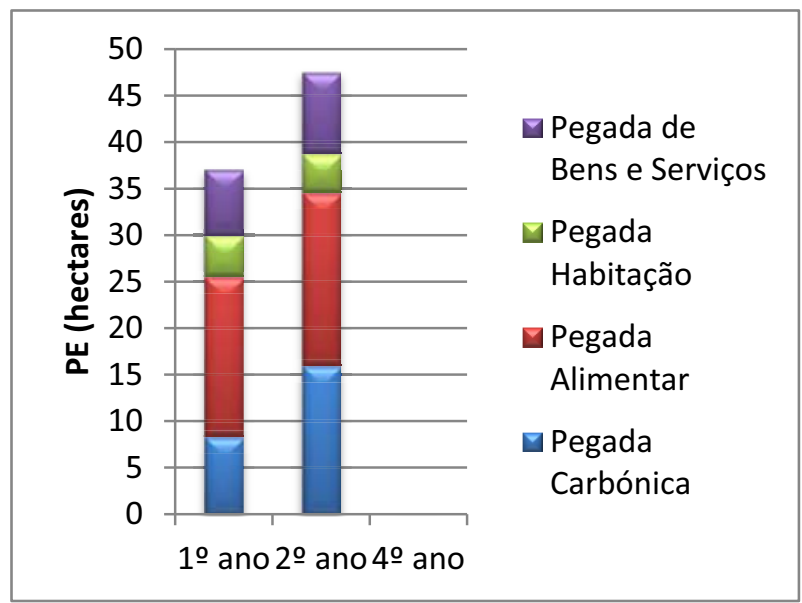

Gráfico 6- PE por consumo alunos de Fisioterapia

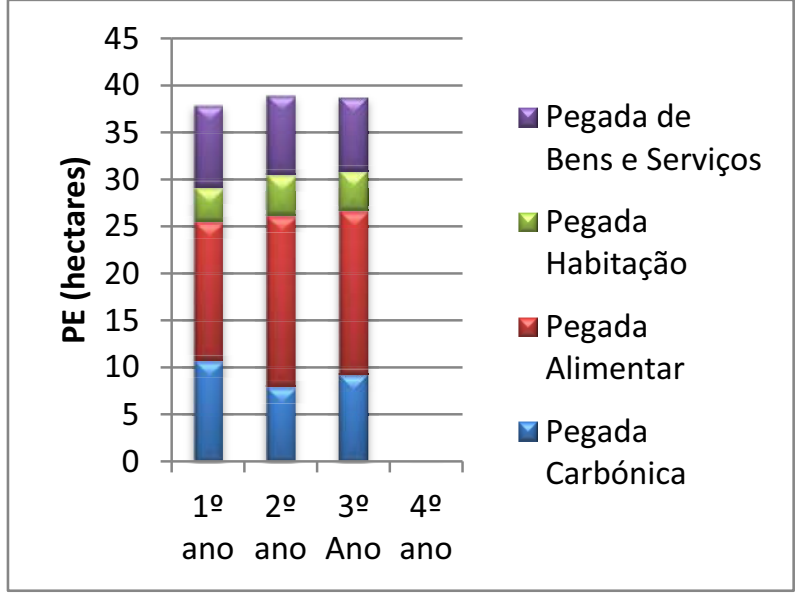

Gráfico 8- PE por consumo alunos de SA

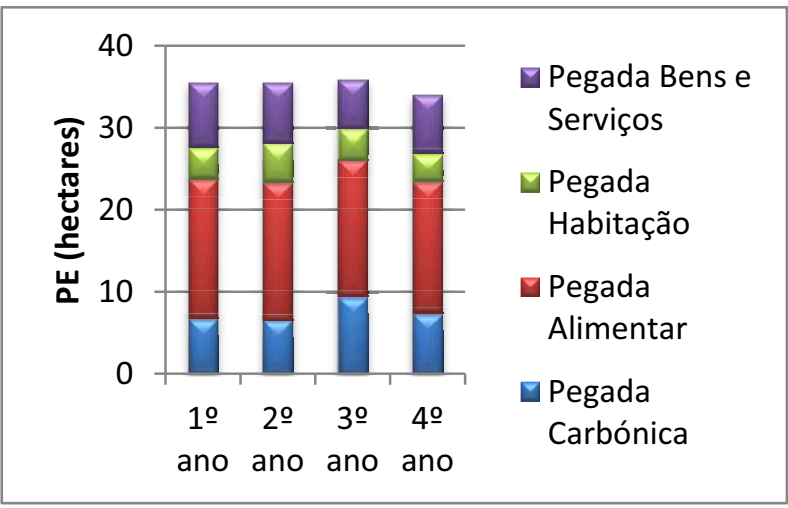


Gráfico 9- PE por consumo Docentes

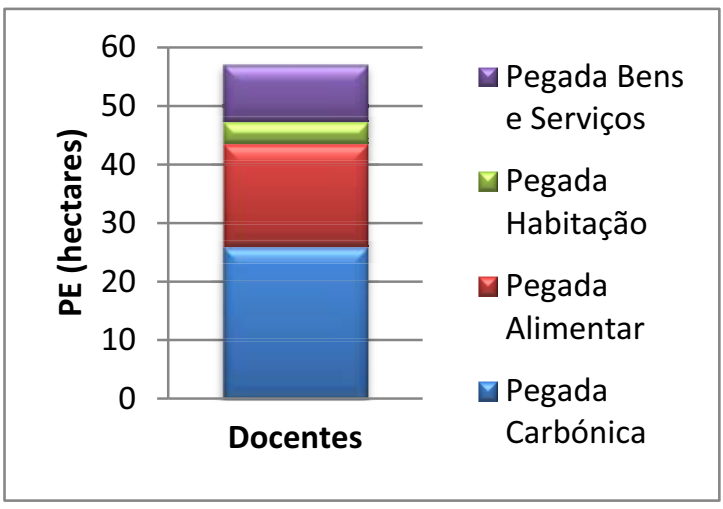

Gráfico 10- PE por consumo dos não docentes

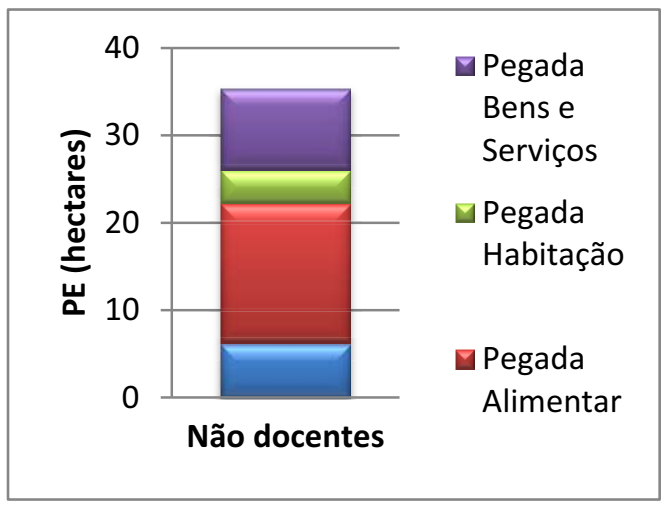

Gráfico 11 - PE por anos ESTeSC

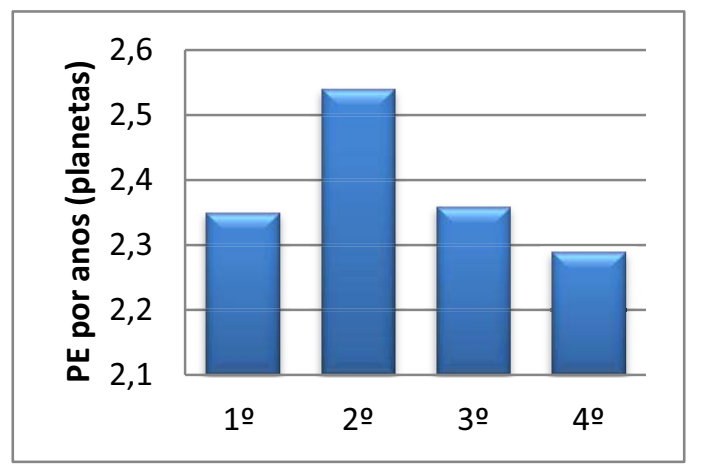

Gráfico 12 - PE por cursos ESTeSC (hectares)

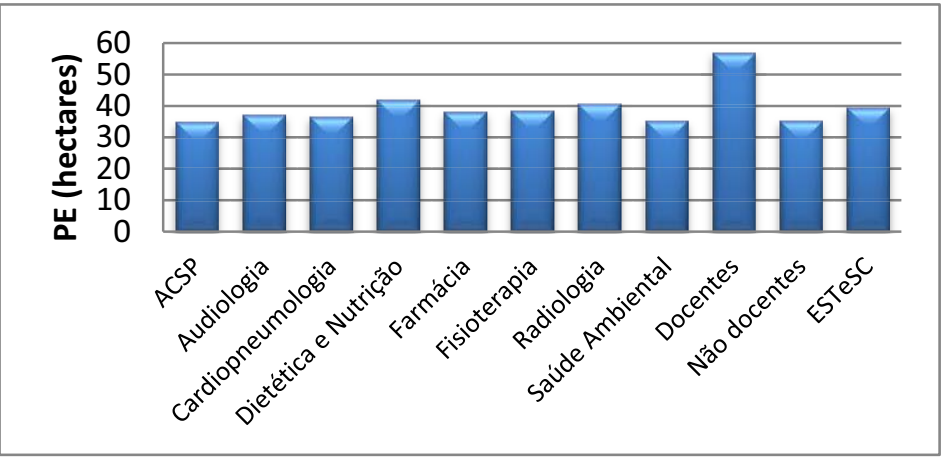

Gráfico 13 - PE por cursos ESTeSC (planetas)

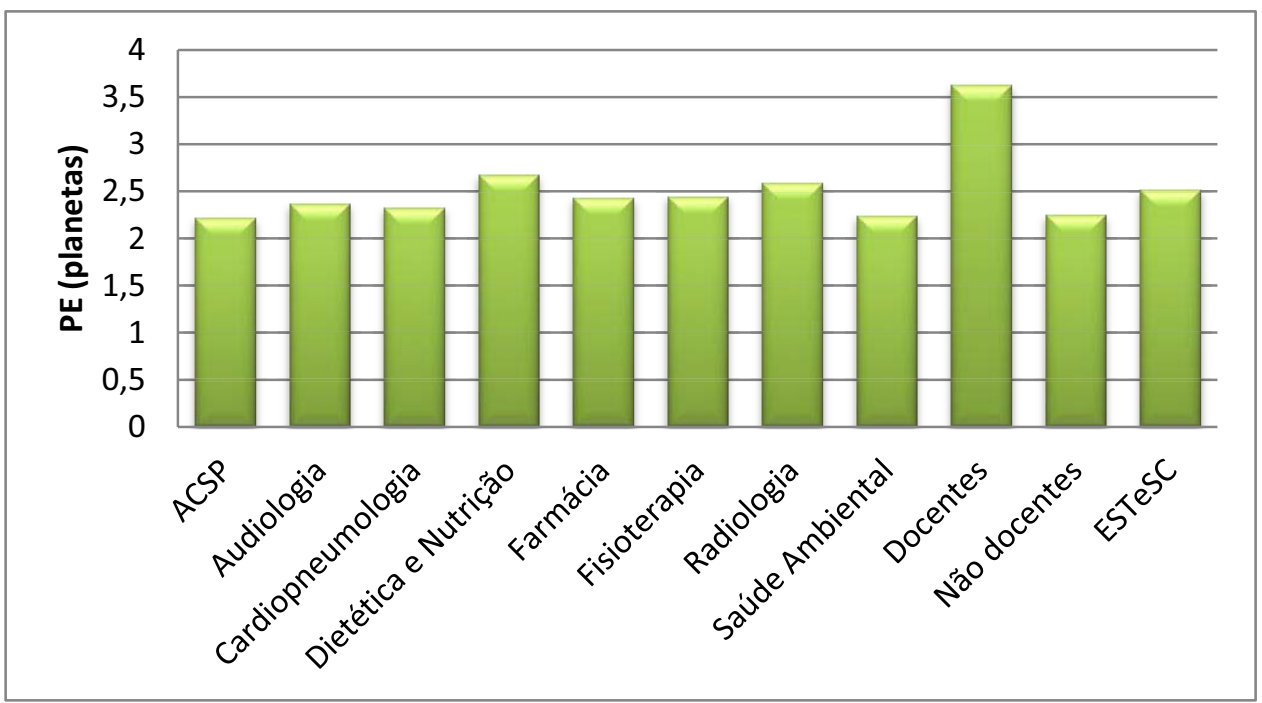


Gráfico 14 - PE ESTeSC (comparação com anos anteriores)

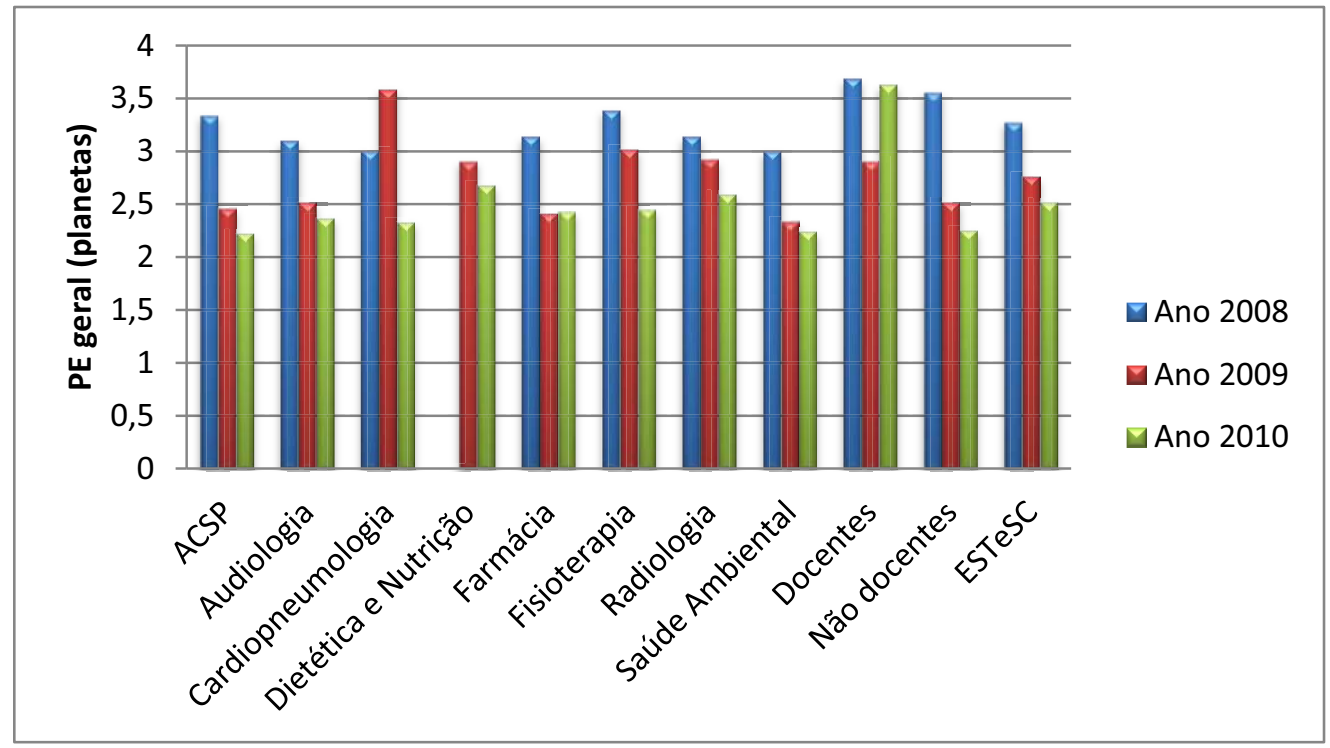

\section{Discussão e conclusões}

\subsection{Discussão}

Relativamente aos alunos dos cursos da ESTeSC é possível verificar que, no geral, o 20 ano é o que apresenta maior pegada ecológica, contrastando com o 1 으 e 4 으 anos. Este facto pode ser explicado pelo aumento de independência e de necessidades de deslocação, conduzindo a um maior consumo de bens materiais, nomeadamente o uso de veículos motorizados em detrimento do uso de transportes públicos. Importa referir que o 4. ano, sendo um ano iminentemente de estágio para a maioria dos cursos, os alunos apresentam a menor pegada ecológica o que terá porventura a ver com o facto de a ESTeSC ser uma instituição do ensino superior com galardão EcoEscolas (primeira do ensino superior no mundo a obtê-lo), que visa adotar e induzir comportamentos ambientalmente responsáveis poderá ter algum impacte no final da formação dos alunos que saem da instituição.

Medidas como o incentivo ao carpooling (partilha de carro para destinos idênticos), separação de resíduos, dicas para a eficiência energética entre outras que são adotadas e instigadas pela instituição poderão estar a passar para os futuros profissionais conforme se pode verificar com o decréscimo da Pegada Ecológica ao longo dos anos de formação, salvo a exceção do 2.ㅇ ano. 
Por sua vez, o curso de Dietética e Nutrição é o curso da ESTeSC que apresenta maior pegada ecológica, sendo o de Saúde Ambiental e o de Análises Clínicas e Saúde Pública os que apresentam menor índice. No entanto, pode salientar-se o facto de o curso de Saúde Ambiental ter uma índole bastante direcionada para a área ambiental, estando estes alunos geralmente mais predispostos e sensibilizados para a adoção de estilos de vida mais sustentáveis e ecológicos. Assim, pode verificar-se que os alunos deste curso espelham no seu quotidiano as vertentes ambientais que lhes são elucidadas durante o percurso académico.

Quanto aos consumos, é possível verificar que a Pegada Alimentar (PA) é a que apresenta maior expressão na comunidade, seguida da Pegada Carbónica (PC), embora se verifique que a PC ultrapassa a PA no grupo dos docentes. O facto de a alimentação dos inquiridos ser baseada numa dieta omnívora, carnívora pode fazer com que o impacte ambiental seja superior a casos de dietas vegan e vegetariana.

Por outro lado, a Pegada Carbónica assume uma posição também relevante no gráfico visto que cada vez mais o Homem está dependente do uso de veículos motorizados. 0 facto de as cidades terem cada vez mais um planeamento disperso e estas se encontrarem cada vez mais acessíveis de outras pelo grande enfoque dado nos últimos anos na construção de infraestruturas rodoviárias faz com que as pessoas tendam a deslocar-se para locais mais afastados do centro das cidades onde a especulação imobiliária impera, optando por preferir a residência em locais cujo valor é substancialmente mais baixo que no centro da cidade, contribuindo dessa forma para um incremento da distância das viagens pendulares entre casa-trabalho-casa. Este facto é paradigmático de uma das consequências da Pegada Carbónica ser elevada em grande parte dos cidadãos e neste caso em concreto verifica-se para o caso dos docentes.

No que concerne ao grupo de docentes e não docentes, pode afirmar-se que são os Docentes o grupo menos sustentável da ESTeSC (com PC bastante expressiva). Neste caso não será alheio o facto de o rendimento económico bem mais expressivo que os restantes grupos fazer a diferença no estilo de vida adotado, seja por via do consumo, alimentação ou inclusive pelas opções diárias que acarretam um impacte substancial para o meio ambiente. 
Segundo dados da WWF (WWF International, 2010), a Pegada Ecológica nacional é cerca de 4,8 hectares por pessoa, sendo que a mundial é de cerca de 3 hectares. A ESTeSC apresenta uma PE de 4,5 hectares, valor inferior à média nacional que, por si, é mais elevada do que a mundial. Dado que a amostra é bastante heterogénea e representa vários locais do país, incidindo mais na região centro, poder-se-á dizer que face aos resultados obtidos existe uma representatividade dos grupos envolvidos. Neste caso os estudantes corresponderão ao grupo de jovens entre os $18-25$ anos, os funcionários corresponderão a uma classe média, uma vez que o espectro vai desde funcionários auxiliares a técnicos superiores e os docentes corresponderão a uma classe média alta.

Comparando os resultados com os anos anteriores, é possível verificar que a PE da ESTeSC desde 2008 (Ferreira, 2008) tem vindo a diminuir na generalidade dos grupos estudados, existindo a maior quebra de 2008 para 2009. Apenas o grupo dos docentes aumentou a sua PE de 2009 para 2010. Aqui não será alheio a abertura de concursos de progressão na carreira que foi realizada em 2009 e que fez com que a condição salarial destes funcionários melhorasse substancialmente, no ano de 2010, e por conseguinte o seu impacte na Pegada Ecológica.

Destaca-se, ainda, que a ESTeSC obteve o galardão Eco-Escolas em 2008, tendo sido a primeira instituição do ensino superior no mundo a obtê-lo conforme já havia sido referido e que desde 2009 para cá tem vindo a fazer alguns investimentos em medidas de eficiência energética, promoção de boas práticas ambientais e sensibilização ambiental. Os resultados ora apresentados poderão ser indiciadores de algum sucesso da iniciativa, uma vez que os resultados têm vindo a descer substancialmente desde 2008.

\subsection{Conclusão}

Com o crescimento e evolução dos hábitos de vida da população existe também uma crescente necessidade de mais quantidade e mais sofisticação dos recursos materiais que a sociedade procura, como se verifica pela diferença no presente estudo com as diferenças entre as Pegadas Ecológicas entre os estudantes/não docentes e os docentes, que por auferirem uma remuneração mais elevada ostentam um padrão de 
vida com base no maior consumo de recursos. Este fator reflete o crescente impacte que cada ser humano está a ter no planeta, adotando um estilo de vida que supera em grande parte das vezes mais de metade do que era suposto, conforme se verifica pela necessidade de ter mais do que um planeta para justificar a pegada ecológica de uma sociedade cada vez mais consumista.

Uma vez que o crescimento da população é constante, assim como as necessidades alimentares, as matérias-primas que servem de base ao consumo diário e o espaço biodisponível para a decomposição/deposição e/ou depuração/mitigação da poluição, torna-se então necessário mensurar os impactes ambientais, tratá-los e comunicá-los com vista à alteração de hábitos de consumo, com vista à adoção de um modo de vida mais sustentável pelas comunidades. Consumir apenas o que se necessita, não adquirir mais do que é suficiente para si mesmo e efetuar a reutilização possível de todos os recursos para que não seja necessário mais do que um planeta Terra para sustentar as nossas vidas é uma peça fundamental na luta contra o aumento exponencial da "Pegada Ecológica" a nível mundial.

Neste âmbito a escolha recaiu num polo de ensino que aglomera estudantes do ensino superior com oito formações diferentes ligadas à área da Saúde, onde entre elas se encontra uma com ligação mais estreita às questões ambientais, Saúde Ambiental, funcionários não docentes com um espectro formativo e de idades bastante lato e docentes cujas áreas de formação são díspares em grande parte dos casos. Acresce o facto de a instituição em causa ser reconhecida mundialmente por um comportamento e indução ambientalmente responsável.

Verificou-se, ainda, com o presente estudo uma descida anual da Pegada Ecológica da instituição no geral, o que pode levar a induzir que esta se deveu ao facto de algumas estratégias de educação ambiental localizadas poderem estar a consciencializar a comunidade académica, assim como o facto de a partir da data em que o estudo começou a ser realizado houve uma degradação da economia nacional o que restringe também o consumo por parte da comunidade, levando por conseguinte a uma diminuição do respetivo impacte ambiental. Acresce salientar que não será alheio, o facto de no ano (2009 para 2010) em que houve uma progressão substancial de carreiras académicas ter havido um crescimento da Pegada Ecológica da classe dos 
docentes o que notoriamente demonstra que quanto maior é o rendimento mensal/anual, maior o impacte ambiental causado pelo comportamento quotidiano.

O presente estudo serviu, ainda, para percecionar melhor o estado de arte do impacte ambiental da comunidade da ESTeSC, bem como a sua evolução ao longo dos últimos três anos. Como limitações ao estudo, destaca-se a fraca adesão ao preenchimento dos questionários, assim como a ausência de algumas respostas em algumas perguntas, das quais foram consideradas como o pior cenário possível o que gerou dificuldades acrescidas na aquisição dos dados. Houve ainda dificuldade em contactar com algumas turmas, dado encontrarem-se em estágio, pelo que o tempo passado na instituição acaba por ser mais reduzido que as restantes turmas o que dificultou um pouco mais o acesso a estes dados.

Conclui-se, que a PE global da ESTeSC tem vindo a diminuir consistentemente nos últimos anos, ao qual não será alheio o fato da instituição ter sido reconhecida com o galardão Eco-Escolas hasteando uma bandeira verde que afere o mesmo, além das campanhas periodicamente dirigidas à comunidade alertando para a adoção de comportamentos mais sustentáveis. Verifica-se, ainda, que os alunos do curso de Saúde Ambiental, são os que têm uma menor Pegada Ecológica o que demonstra que cidadãos mais informados e portanto conscientes dos problemas e causas dos impactes ambientais refletem um comportamento ambientalmente mais responsável e com menor impacte ambiental.

Pretende-se que o presente estudo tenha continuidade ao longo dos anos e que a determinação da PE seja uma ferramenta valiosa no diagnóstico e sensibilização do estilo de vida da comunidade académica da ESTeSC. Esta pode e dever ser replicada por outras instituições de ensino, instituições públicas, privadas e até simplesmente a cidadãos com vista à consciencialização à Sustentabilidade. Entende-se que a presente boa prática deve ser replicada e divulgada por forma a estimular e incentivar instituições congéneres. Esta tem ainda uma importância de feedback às chefias como indicador de Sustentabilidade Ambiental que pode ser potenciado e estimulado à melhoria contínua da instituição. 


\section{Referências bibliográficas}

Coelho-de-Souza, C. (2009). Proposta de método para a avaliação da sustentabilidade ambiental de pequenos edifícios. Porto Alegre: Universidade Federal do Rio Grande do Sul.

Ferreira, A. et al. (2008). Pegada Ecológica da Escola Superior de Tecnologia da Saúde de

Coimbra. Coimbra: ESTeSC: Departamento de Saúde Ambiental.

Footprint Network. (s.d.). Obtido em 3 de Junho de 2011, de http://www.footprintnetwork.org/images/uploads/2010_NFA_data_tables.xls

Parente, A. (2007). Indicadores de Sustentabilidade Ambiental: Um estudo do Ecological Footprint Method do Município de Joinville - SC. Biguaçu - SC: Universidade do Vale do Itajaí.

Pedrosa, E. et al.; (2009). Pegada Ecológica da Comunidade da ESTeSC - 2009. Coimbra: Escola Superior de Tecnologia da Saúde de Coimbra.

Pereira, T. et al.; (2011). Portuguese Informative Inventory Report: 1990 - 2009. Amadora: Agência Portuguesa do Ambiente.

WWF International. (2010). Living Planet Report 2010: Biodiversity, biocapacity and development. 